\title{
Resilient safety anti-terrorism city terrorism as a new challenge in contemporary Iraqi city
}

\author{
Enas Dhiyaa Hadi ${ }^{1}$, Abd Al-hussain Al Askari ${ }^{2}$, \\ ${ }^{1}$ Institute of urban and regional planning for post graduate studies, Baghdad University \\ ${ }^{2}$ Institute of urban and regional planning for post graduate studies, Baghdad University
}

\section{Article Info}

Received, 2019

\section{Keyword:}

Resilience. terrorism attacks Anti-terrorism city. safety city

\begin{abstract}
Resilience against a variety of common and disruptive threats of terrorism is increasingly valuable in terms of the way communities are designed, operated and how urban practitioners are working to improve the community safety level. This is especially true of communities and cities, activities that are considered susceptible to terrorist attacks. This work explores a robust approach to create a safe climate, safety societies in ways that can decrease the likelihood and effect of a terrorist attack.
\end{abstract}

In specific, the research problem was: The inability of our cities to face the Unpredictable challenges (terrorism attacks) with a resilient flexible strategies that's contributed in reduces the urban safety.

The research assumes: adoption of resilience strategy will contribute to increase the city safety against the Unpredictable challenges (terrorism attacks).

The research aimed to: reach more resilient safety cities that can confront the Unpredictable challenges (terrorism attacks) through its community and built environment.

The research methodology was: Explain the concepts of resilience, resilient cities and its characteristics and approaches, then adopt an integration approach to drop it on the characteristics of safety city as access to the indicators of resilient safety anti- terrorism city with Canada's experience antiterrorism attacks as case study.

The important conclusions were: There is necessity for professionals with a culture of terrorism to set up alerts and alarm the people before the risk entering. Resilience proxies depend on urban system type and its components that's differs from place to another, one of the robust resilient city approaches was: integrated-forward looking approach it is not only react to emergent threats, however may draw trends to survive, take off the city systems.

\section{Corresponding Author:}

First Author,

Enas Dhiyaa Hadi

center of urban and regional planning for post graduate studies

Baghdad University,

Email:annosa.30@gmail.com 


\section{Introduction}

Our cities face diverse challenges and threats on all systems of life at many levels. One of these threats is terrorism attacks. Responds of the city and its society to the terrorism or threat of terrorism is fall under the term of "anti-terrorism". Anti-terrorism defines:

Defensive concept used to reduce the vulnerability of individuals and communities to terrorist acts. This includes Strategic plans, material and strategic measures in order to create a safer, resilience environment before threats or to response to terrorist threats.in this research: anti-terrorism concept which is more focuses on urban system is carrying the concept of safety resilient city.

\section{Material and methods}

This work is done by mixing technique: the first part is achieved by defining and evaluating the investigation area by the author. The second section involves a form survey for gathering direct information from either the consumers of the investigation area selected or disseminating the findings to everyone by implementing the inductive approach.

This research is also focused on the -dimensional charts, photographs of the investigation area by the analytical approach descriptive.

\section{Theory}

\subsection{Towards a new urban paradigm.}

The City that we need is built and developed to be more robust, agile, healthy and continuing risk assessment and capacity building for local communities, individuals and stakeholders for preparing to handle, heal and learn from chronic stress and acute shocks.

This works, where possible, to avert and deter these incidents, shielding vulnerable inhabitants before, during and after the incident. It understands that it is just as robust as perhaps the most vulnerable and disadvantaged people and seeks to ensure long-term survival, quality, and safety of life. The City that wants is regenerative, the energy effective is preserved by itself. This acknowledges the carrying capacity and shortcomings of the supporting structures and respects system services for the characters they have in public health, protection and security, livability and aesthetics. [1]

\subsection{Resilience Main Concepts}

Resilience arises from the Latin word: resilio, resilire or reseller, it is content" to bounce back" or "bounceforward".

Resilience origins from the field of ecology, characterizing the adaption of an eco-system to changing with foreign conditions, it is Also used in social sciences and psychology, later, Resilience is used in the context of urban studies as well as .Here resilience on behalf of "city hazards and risks" in this research it has been concentrates on resilience with safety to play a role particularly in absorb the trauma of terrorist threats. [2]

Various academic fields appeal resilience concept to depict the specified system's response to a disturbance; Definitions of resilience from different fields are differ, but they cast all on two key visions:

The first of which is the entity being depict as Engineering resilience, here resilience: depict the materials capacity, withstand stresses for physical structures, shocks without functional collapse or change the structure. Resilience in this pattern is a performance or occurrence focused on how a substance or system can survive pressure when "anything is deeply rooted in the object's structure".

Second: environmental resilience: the concept of individuals, societies, organizations as a process is implemented instead. Ecology has introduced durability to reflect natural systems. Resilience in the ecological field indicates the conversion of a particular system into a largely useful gear for coping with unforeseen threats [3]. See the following figure (1):

The researchers see Resilience concept could be branched to: 
1- 1-Hard components: that's connected with (engineering resilience) include: infrastructure-build environment.

2- 2-Soft components: that's connected with ecological resilience include: natural, social, institutional, and cultural system components.

3- The resilience urban system we need is gathering the two components above.

\subsection{Resilient approaches:}

Resilient city should be implementing a balanced approaches grouping: [4]

- Approach to urban infrastructure: energy, water communications to sanitation and transport systems. We are critically important for the response of emergency, neighborhood restoration, and economic recovery.

- Approach to social resilience: is a group and society's ability to cope with and respond to challenges or adjustments.

- In tandem with land usage planning, solutions to environmental conservation to improve sustainability in urban areas allow utilize of the natural landscape and therefore could substantially reduce the projects costs of urban infrastructure.

- Urban promotes key approaches: social networks, livelihoods, housing, and infrastructure for extremely vulnerable slum households' settlements.

- Deciding how to prioritize efforts in resilience needs an understanding of current and future dangers.

- A key approach to the planning of disaster and emergency: risk could never be completely eliminated.

- Financial approach: urban catastrophe adaptation must minimize the disaster's passive effect on communities and individuals, the public and private sectors.

- Safety, security against crimes, terrorism attacks approach. [5],- this approach is the core of our research approach.

\subsection{Resilient dimensions:}

In 2006, the Multidisciplinary Center for Earthquake Engineering Research (MCEER) made one of the first efforts to break down resistance into its structural parts [6]. The MCEER defined four resilience dimensions:

- Economical

- Social

- Organizational

- Technical-

Several researchers subsequently review ten models that try to determine social resilience and say which the concept is interpreted utilizing five dimensions: [7]

- Natural

- Physical,

- Institutional

- Economical

- Social

\subsection{Resilience in urban system:}

The urban system could be defined in many aspects, based on the significance of the components and the location. In this initial phase of our research, we propose the division of the urban system have five basic components, which significantly effect on the resilience of the system. 
Built environment, infrastructure, community and culture, institutions and city activity. Buildings are physical skeleton of the urban system that is united in the whole by open space and powered by infrastructure and the city activities, community is lifeblood and a soul of the system, institutions represents the Law that's governing the urban environment. Nevertheless, it must be noticed that the suggested division might be spread by additional component(s) based on the analysis of urban system's priorities and aim. [8]

\subsection{Resilience Proxies:}

\section{- Diversity:}

Core concept in resilience theory, diversity, it is enable systems to reform multiple coping strategies, helping them remain comparatively constant through change and supplying them with higher potential for innovation. Diversity of uses, transport modes is linked to livability, economic attractiveness, healthier lifestyles. It is even beyond any appointed function the very way urban space is divided and subdivided gives places an essential capacity to hold diversity, enabling them to succeed in spite of changes in economic conditions, culture and technology. It is also supporting spread of innovation through knowing spill-overs [9].

\section{- Connectivity:}

Depicts the ease of flow within a system or across systems. In resilience high and low connectivity can be eligible, the first spreads knowledge expansion and recovery after disturbance, the second reduces the diffusion for disturbance and enables memory preservation. Although when this way brings fragmentation, it inspires negatively in the urban system, both internal and external connectivity are greatly effect on people activity and the location and intensity of actions. [10]

\section{- Integration and Inclusiveness: [11]}

Integration: Collocation between community structures increases decision-making continuity and supports that all resources promote a shared goal in turn. Integration is noticeable in and between robust networks and their function over various levels. Replacing data between processes helps them to operate together and respond quickly in the city by shorter feedback loops.

Inclusiveness: Incorporation proves the need for consultation of scope, communities of engagement. This might be the most fragile set utilized. It is anathema to the principle of resilience to resolve the shocks, pressures experienced by one field, area, or society in the displacement of others. An inclusive approach leads to a common meaning, responsibility and collective vision for creating urban resilience.

\section{- Participation:}

Participation through strong correlation of all relevant stakeholders is considered essentially to building resilient city .It helps to build trust and linkages needed to improve legitimacy of learning and authority during decision making processes. If a diversity of people participate, from a diversity backgrounds and perspectives, it can detect perspectives that may not be earned through more traditional scientific processes. Participation can also help support the link between gathering information's and decisionmaking. [12]

3.7 Resilience city: Resilient city is the city where there are: [13]

- Minimum human risk.

- Multiple employment and livelihoods.

- Safeguards effective for human life and health.

- Support of community and Collective identity.

- Law rule and comprehensive security.

- Effectiveness delivery of vital resources.

- Credible mobility and communications. 
- Effectiveness management and leadership.

- Large investors in sustainable growth.

\subsection{Terrorism with cities, definitions: [14]}

The term ' terrorism ' does have its origins in the Latin word 'terrere' meaning ' fear'. The Greek word for terror is "tromokratia" that is indicating serious from the word "tromos." Terrorism is a trend that may have plagued almost every society in the world for decades.

Traditionally, the term has been utilized in $105 \mathrm{BC}$ by ancient Romans to describe the fear of a brave warrior tribe planning for an invasion by a mighty warrior tribe. This assumption is taken into consideration several years later during Maximillian Robespierre's bloody reign during the Revolution of French.

Terrorism describes a process of democratic movement that carried out (the Great Terror) from September 1792 to July 1794. The number appears early in the Dictionary of the French Academy in 1798, although the term appeared at the end of the 18th century and previous experiences also arisen.

Definition of the United Nations:[15 ] Criminal acts determined or prepared to cause a terror state in the general public, individuals or groups or specific individuals for a variety of reasons: organizational, political, they are in any unwarranted condition, regardless of the political, ideological, religious, philosophical, racial, ethnicor other factors that might be invoked to validate them.

In fact, on the basis of features, we differentiate terrorism from other forms of conflict and violence: [16]

1- This violates control of expectations, challenges, demonstrations, and opposition.

2- $\quad$ It is designed and planned to enter an atmosphere of extreme fear.

3- $\quad$ It is aimed at broad objectives comparison with the urgent victims.

4- $\quad$ It includes strikes on unintended and abstract targets, like civilians.

5- It is regarded by the community that it occurs as additional-normal, that is, in the technical sense that it violates the rules governing, fighting, protesting and dissenting.

6- It is primarily, but not necessarily, utilized to manipulate states, societies and specific social groups ' political behaviour.

\subsection{Terrorism Approaches: [17]}

- The methodology of Instrumental.

- The methodology of Organizational

- The methodology of Economic

- The methodology of Psychological

\subsection{Resilience against terrorist attacks in safer cities:}

Safer Cities is: based on local government instruments, which encourage good governance, effective strategic management, and planning as resources for dealing with terrorism, violence, tension and insecurity in human settlements and cities. It is a multi-sectoral and multi-disciplinary solution applied on a city-level (communitybased) scale, focusing on stakeholder participation, cooperation to ensure social security and safety. The cities ' problem is the terrorist attacks in the political, physical and economic city centers. The Safer Cities Project describes good government and healthy cities as mutual: once people are allowed from terror, social contact is essential between individuals, associations and government institutions. [18]

Therefore, a holistic solution to urban defence focused on three major pillars: [19]

1- Prevention of institutional violence - which include frameworks for enforcement and legislative;

2- Prevention of social violence - which include targeting at-risk youth and gender activation. 
3-Prevention of social abuse - based on the physical surroundings. This incorporates the ideals of deterrence of urban terrorism into the precautionary standards of defense. Intrusion in community stability aimed at reducing urban instability by improving the following: incorporation of cross-cutting security issues to enforce the New Urban Agenda.

Within its areas of expertise, most municipalities explore, create and sharing experiences, best practices and practical community solutions. All with the goal of eliminating activity that encourages extremism and aggression. From this point of view, the Safe Cities project proposed six goals to build a safety resilience city: [20]

1- $\quad$ Safe spaces around the city and community.

Build a town that is available to everybody.

2- $\quad$ Safe Online Security Sphere.

Develop a digital domain with a community of e-safety and secure online communities.

3- $\quad$ Strong Families.

Take action with families to protect children.

4- $\quad$ Secure management of the government and organizations

Supporting public institutions with progressive policies and actions to protect citizens.

5- $\quad$ Clear Youth Interaction

Strengthen the voices of young people.

6- $\quad$ Safe and clean societies.

Attaining social security and protection and activating the concept of gender.

\subsection{The researcher's analysis for Anti-terrorism, resilient city proxies are summarizing in:}

- Integration:

- of social, cultural, economical, institutional with reciprocal feedback and interdependence. To build the concepts of the context to physical built environment.

- Connectivity:

- social, cultural, economic, institutional through social coherence, the principle of multiculturalism, Knowledge and ideas Exchange, safety Communication.

- Diversity:

- multi culture people, multi ideas, multi languages, multi functions, decentralized.

- Inclusiveness: engaged and benefit a range of actors and systems that's consisting: social, cultural, economical, institutional factors.

- Participation: it is engagement of all relevant stakeholders and it is considered a fundamental process to build city resilience.

If we mix the indicators to find new matrix, see table no (1): 
Table no(1),resilient safety city indicators derived

\begin{tabular}{|c|c|c|c|c|c|}
\hline \multirow[b]{3}{*}{ e: } & \multirow{6}{*}{ 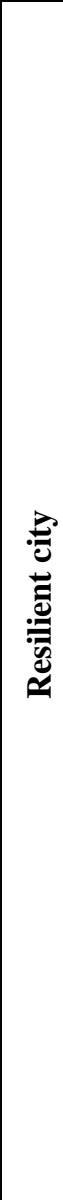 } & \multirow{2}{*}{$\begin{array}{l}\text { Resilient safety } \\
\text { city -matrix of } \\
\text { indicators }\end{array}$} & \multicolumn{3}{|c|}{ Safety city } \\
\hline & & & $\begin{array}{c}\text { Social-cultural } \\
\text { preventation }\end{array}$ & $\begin{array}{l}\text { Urban planning and } \\
\text { urban design- spatial }\end{array}$ & $\begin{array}{c}\text { institutions and } \\
\text { economic } \\
\text { enforcement }\end{array}$ \\
\hline & & Diversity & $\begin{array}{l}\text { The city has } \\
\text { diverse component } \\
\text {,ethnic, } \\
\text { Religious } \\
\text { culturs. }\end{array}$ & $\begin{array}{l}\text { There is a diversity } \\
\text { places, diversity activities }\end{array}$ & $\begin{array}{l}\text { There is diverse in } \\
\text { institutions and } \\
\text { organization, } \\
\text { Economic forces } \\
\text { that's stand against } \\
\text { terrorism }\end{array}$ \\
\hline & & $\begin{array}{l}\text { Inclusiveness } \\
\text { And social } \\
\text { coherence }\end{array}$ & $\begin{array}{l}\text { Social-cultural } \\
\text { interaction and } \\
\text { cohesive } \\
\text { relationship, } \\
\text { presence and } \\
\text { harmony feelings } \\
\text { among the } \\
\text { inhabitants }\end{array}$ & \begin{tabular}{l||} 
city places, \\
neighborhoods is safety \\
to allow social gathering \\
city places, \\
neighborhoods is enough \\
to allow social gathering
\end{tabular} & $\begin{array}{l}\text { There is feeling of } \\
\text { trust between the } \\
\text { city inhabitant and } \\
\text { the institutions } \\
\text { Economic forces. }\end{array}$ \\
\hline & & $\overline{\text { Connectivity }}$ & $\begin{array}{l}\text { Safe, easy social- } \\
\text { cultural connection } \\
\text { and interaction }\end{array}$ & $\begin{array}{l}\text { Sufficient, clarity places } \\
\text { that's ensure access to } \\
\text { connect with all its parts }\end{array}$ & $\begin{array}{l}\text { Safe, easy } \\
\text { connection and } \\
\text { interaction between } \\
\text { the institution - } \\
\text { inhabitants, } \\
\text { Economic forces- } \\
\text { inhabitant }\end{array}$ \\
\hline & & Participation & $\begin{array}{l}\text { Citizen participate } \\
\text { on decision } \\
\text { making }\end{array}$ & $\begin{array}{l}\text { Citizen participate on } \\
\text { urban planning decision } \\
\text { making }\end{array}$ & $\begin{array}{l}\text { Institutional - } \\
\text { economic support }\end{array}$ \\
\hline
\end{tabular}

researchers based on what's mention above.

From the resulting indicator matrix, the questionnaire form was extracted in the shape that has facilitated the research purposes and aims.

\section{Previous experience:}

\section{1 Canada resilient safety city}

Creating a safe city for resistance-the anti-terrorism approaches of Canada: [21]

A. Canada isn't just a terrorist defense. Throughout Canada, there are a number of international and domestic radical groups. Many participate throughout terrorist activity abroad, and support terrorism beyond the boundaries of Canada. Building Counter-Terrorism Resilience clearly sets out Canada's integrated way of tackling terrorist threats at home and abroad. This outlines that Canada embraces each other's regional, international and national efforts to support People and the interests of Canada. The goal was to defend Canada "The B-first priority of the Government of Canada is to protect Canada and the safety and security of Canadians at home and abroad."

It needs an integrated method, in partnership with international partners and key allies, not only from the Canadian Government but also from all levels government, law enforcement agencies, the residents and the private sector. Citizens have also a responsibility to work with security staff and government and to create strong and supportive local communities. A genuinely sustainable Canada 
will only be accomplished when these responsibilities are shared. The strategy of Canada needs to be adaptable and forward-looking not only to respond to evolving threats, but also to recognize and comprehend emerging technologies.

\section{B. Description of Canadian terrorist activity:}

The scope of terrorist activity requires an act or omission performed, within or outside Canada, for a political, religious or ideological intent intended to intimidate the population with regard to its safety, particularly economic security, or to force an individual, government or organization (in or outside Canada) to do or refrain from doing any act, and that includes the concept of terrorist activity.

\section{Terrorism challenges Canada's wealth:}

1- Regional terrorism focused on domestic problem.

2- $\quad$ A number of threats to international terrorism.

\section{Strategic factors that pose the threat of terrorism:}

1- Globalism.

2- Rapid change in technology.

3- A world with rising networking and unstable states.

That created new and different flaws that could be abused by terrorists. Governments should therefore remain competitive with a growing technological climate, the emergence of more advanced weapons, particularly weapons of mass destruction, new developments in technology, and the accelerated people flow, capital and innovations all over the globe.

The core concepts of the plan are focused on fundamental Canadian ideals, and also the workable history of Canada in dealing with terrorism, for these challenges. A profound commitment to equality, the law rule, regard for individual rights and pluralism has influenced the Canadian experience. It is focused on openness to creativity and inventions, as well as to individuals from all over the globe. It is also a culture where bigotry and racial violence are opposed.

Creating durability is the fundamental principle of the policy. The ultimate objective is a Canada in which communities and individuals could reject violent extremist agendas and culture can avoid terrorist attacks.

\section{E. The six basic principles of the approach:}

1. Building of a sustainable community.

2. Terrorism is a felony and is sure to be punished

3. Compliance with the law rule

4. Partnerships and coordination

5. The response is proportionate and calculated

6. A forward-looking and versatile strategy

The technique works via four components that complement each other: Avoid Identification, Deny, and Respond. All policy operations are related to one or more of such components, [22]

\section{2 Canada's comprehensive community safety policy}

1-Preventing: For preventing people from becoming involved in terrorism. Canada's goal is to identify and reduce contributing factors. Terrorism. By engaging actively with people, societies, and regional partners, and by researching to fully understand and counter these factors. The Prevent aspects also allow law enforcement to develop strong community engagement capacities, including improved cultural and language sensitivity skills required to connect with different communities in Canada.

Based on giving positive alternate narratives that highlight Canadian society's free, diverse and inclusive existence and aim to promote a greater sense of Canadian citizenship and belonging to all see Figure No (1).

Figure no (1) Canada resilient safety city strategy 


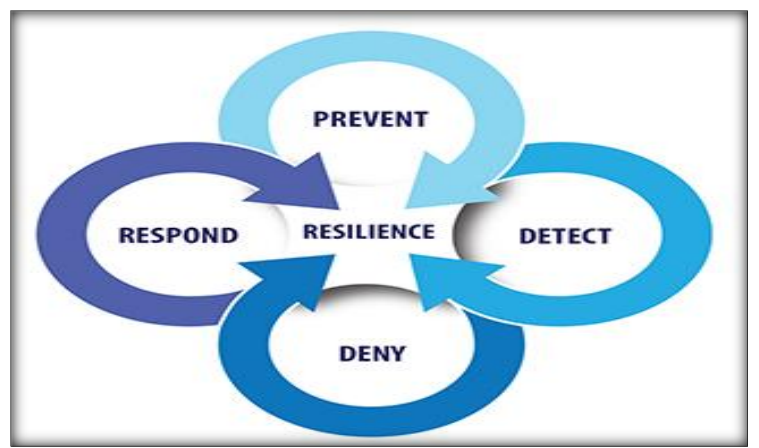

source:the researchers depends on whats mentioned

2- Detect: To identify the actions of people and organizations that might pose a threat to terrorism

There, the terrorists themselves, their skill and the essence of their intentions are required to know. Identifying who supports their efforts is also important. Canada does this via research knowledge and evaluation. Good knowledge and expertise are needed, solid understanding of the risk environment's tactical dynamics, robust cooperation and sharing of information with domestic and international partners. Want for safety of contact. In aid of criminal researches and risk analyses, exchange and review data. Continues to operate a Critical Infrastructure Awareness Group to analyze national defense physical and cyber risks. Gives terrorism sensitivity training for first responders on major factors of terrorist operations, strategies and procedures to help identify attacks as soon as possible.

\section{3- Deney: To restrict the tools and resources for extremists to conducting their operations to protect} them.

Denying extremists access to resources abroad and trying to secure global hot spots could impede the flow of immigrants and capital and the procurement of arms, including weapons of mass destruction, could prevent possible vulnerabilities in networks of transport, protection's border, critical infrastructure and cyber security; and investigating and prosecuting intrusive individuals.

4- Response: To react to terrorist activities in a proportionate, swift and coordinated manner and to minimize their impact.

It includes the ability to resolve a multitude of terrorism attacks, preserving rapid response and reconstruction capabilities for critical infrastructure, ensuring continuity of government and basic social services, displaying government leadership by successful public communications.

All these requires: integrated national and local response, unified management and planning control center during crucial accidents and major events. Good interactions in relation to a terrorist incident between the state and Canadians.

\section{1 Anti-terrorism, resilient, key predictors of safety in the city:}

The authors split it into four categories according to the robust, healthy city's urban structure:

1- The systems of Social-cultural.

2- The systems of Built environment.

3- The systems of Institutional.

4- Events in the region-economic forces.

\section{2 Al-kadhimiya-alanbarien (neighbourhood no.421):}

Each article includes a brief summary of the motives and influences in al-Kadhimiya. Al-Kadhimiya district is situated north of Baghdad, around $(5 \mathrm{~km}$ from the west side of Baghdad and the right side of the Tigris River next to al-Karkh.). Kadhimiya is linked to al-Adhamiya Bridge, which connects with al-Muhit Street around it. Imam Musa al-Kadhim, And Imam Muhammad al-Jawad, are buried in this cemetery. Such two imams have great value in the Muslims ' hearts and have continued to visit them even after their death [23] (alanbarian neibourhood) for about a few minutes of al-Kadhimin shrine.

Large numbers of people were allowed to set up some individual works in the area to attract tourists for the sake of profit, which is why the city is prosperous in housing and social infrastructure, slowly attracting its characters. Islamic ideals and principles are reflected in planning and design. At almost the same period, in 
terms of the harmonious urban fabric and the trend of inward orientation, rely on local models of Mesopotamian architecture.

The roads led to the connection between the Kadhimiya district and the surrounding areas was intensified by rapid, unintended development of commercial activities on both sides. This was followed by a rise in land prices and an increase in construction along these streets, which triggered population movement to the outskirts of the city.

As a result of rapid development (regardless of whether natural growth or development as a result of migration and the extension of Baghdad to al-Kadhimiya and its outskirts, and also inner immigration from Kadhimiya to the suburbs as a result of the commercial activity intrusion), the inheritance is increasing in the city. This is why the development of populated areas in the al-Kadhimiya region is stimulated. The region is restricted to five ways, and the citizens go according to their kinetic instructions in every entrance to many locations. For map number (1)

Due to the existence of al-Kadhimin's shrine, the spiritual element was the dominant factor in the urban structure development of this area. It is the central focus in the creation of the physical and social framework of the city. This structure of organic coherent represents the unity and social cohesion underlined by the Islamic religion is mostly a circle cover round the shrine adhered and accepted. Some changes in the architecture are happening with the new major roads because of outside pressures from other communities and automobile entry. However, if we delve more into the old fabric likes (421) neighbourhood, we find another mass formations form of housing units that belong to Iraq's Islamic style. As a result of an association between the area's desires for security and confidentiality with their local environment, it gave a sense of identity and safety with a strong connection between the passer through the alleys and surrounding blocks, which enhanced the social ties between this area's communities. All of this represents personal security in terms of rituals and traditions [24].

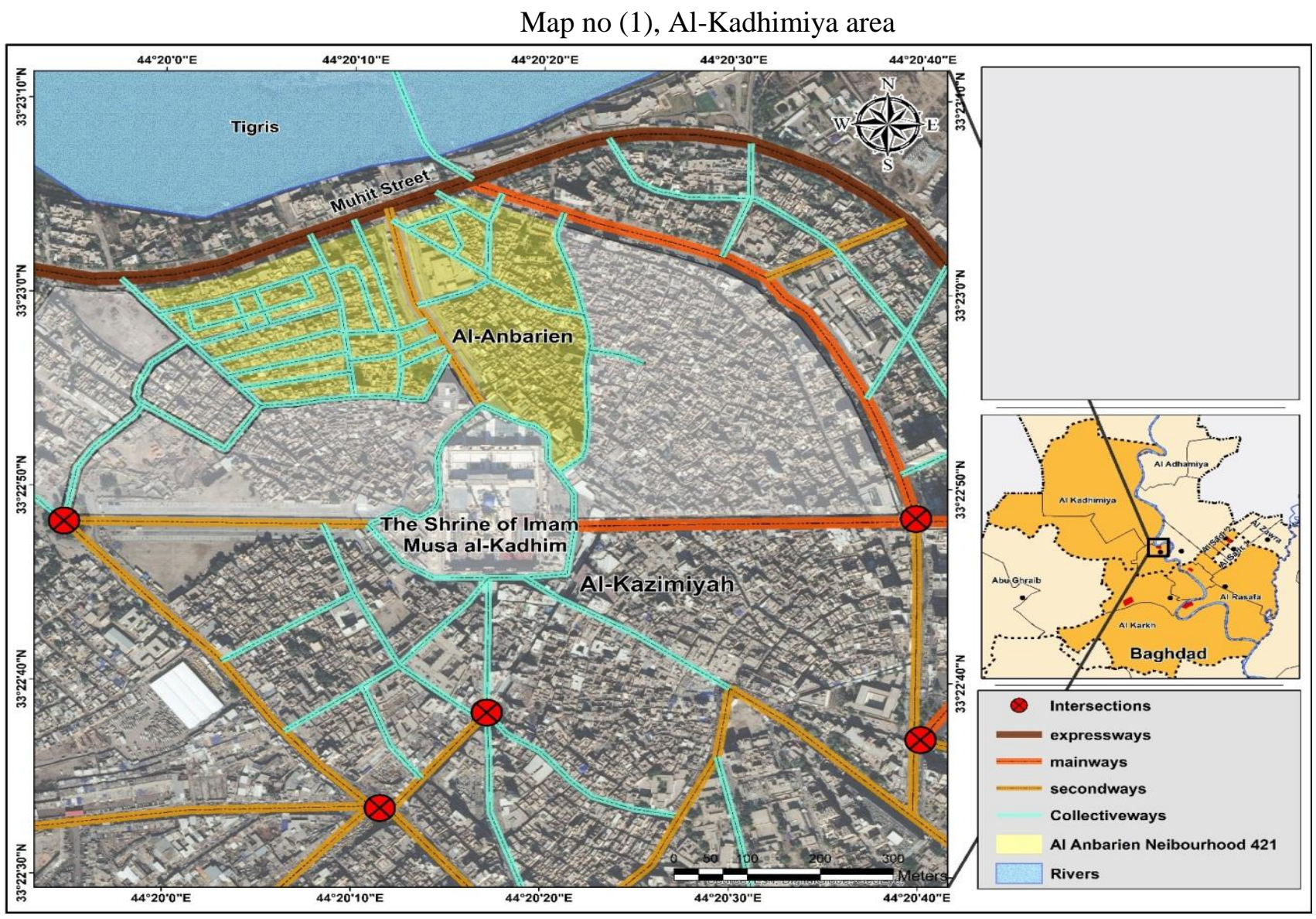


Source: the researchers by GIS application

\section{3 The Survey procedure parts and results:}

The area of study includes the development of a survey method which satisfies the research goals depending on the quantitative dimensions and on the theoretical framework. By using this system of terminology (that was an indicators extract) and formulating it in practical terms by translating it into a number of questions, it comprises two sections, part one on: the details of the recipient (which involves age, race, level of education, years of residency in the city, family and profession, etc.) in terms of knowing the essence of the co-recipient. Part two deals with the key safety-resilient city indicators and their measurements as sub-indicators, it appears in a table as a question list form, it depending on the Scale of Likert On a five scale point: (bad, low, excellent, reasonable, and strong).

The key metrics were: heterogeneity, social coherence, communication, security and safety, with five dimensions: (cultural, institutional, spatial, economic, social). The outcomes are appearing in table no (2), fig no $(2)$

Table no (2), questionnaire form results in study area

\begin{tabular}{|c|c||c||c||c|}
\hline dimension & $\begin{array}{c}\text { Diversity } \\
\text { indicator } \\
\text { results }\end{array}$ & $\begin{array}{c}\frac{\text { Safety \& }}{\frac{\underline{\text { security }}}{\text { indicator }}} \\
\text { results }\end{array}$ & $\begin{array}{c}\text { Social } \\
\text { coherence } \\
\text { indicator } \\
\text { results }\end{array}$ & $\begin{array}{c}\text { Connectivity } \\
\text { indicator results }\end{array}$ \\
\hline \hline Economic & $62 \%$ fair & $\underline{95 \% \text { excellent }}$ & $65 \%$ fair & $60 \%$ fair \\
\hline \hline social & $65 \%$ fair & $\underline{85 \% \text { strong }}$ & $85 \%$ strong & $65 \%$ fair \\
\hline \hline spatial & $\underline{70 \% \text { fair }}$ & $\underline{95 \% \text { excellent }}$ & $\underline{85 \% \text { strong }}$ & $\underline{70 \% \text { fair }}$ \\
\hline \hline institutional & $60 \%$ fair & $\underline{85 \% \text { strong }}$ & $65 \%$ fair & $65 \%$ fair \\
\hline \hline cultural & $68 \%$ fair & $\underline{85 \% \text { strong }}$ & $85 \%$ strong & $65 \%$ fair \\
\hline \hline average & $65 \%$ & $\underline{89 \%}$ & $77 \%$ & $65 \%$ \\
\hline
\end{tabular}

Source: the researchers by spps application

Figure no (2), Al-Kadhimiya questionnaire form results

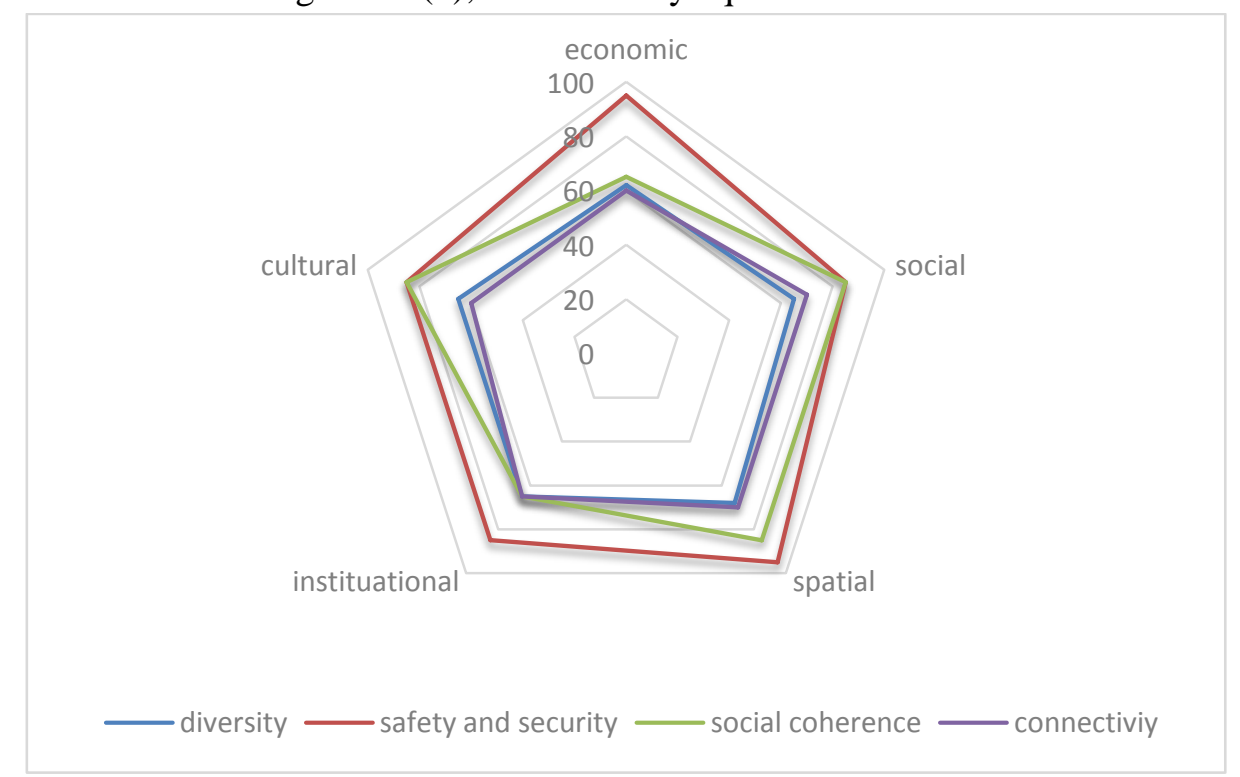


Source: researchers depends on the questionnaire form results

\section{4 discussion and conclusions:}

al-Kadhimiya achieved the highest percentage in security and safety index as a major indicator al-Kadhimiya area achieved the highest percentage of spatial dimension in all indicators

We infer from this that the existence of self-ingredients in that place is allowed to achieve these ratios, it may be social-economic- institutional cultural according to the spatial dimension

This leads us to derive a new concept, which is called the place competence to achieve the resilient of the place. Here in al-Kadhimiya:the place competence is: security and safety that's given the areas shrines , shrines are contributed in cohesion of the social fabric against terrorism as a common competence in the place.

After safety and security, Other resilient anti-terrorism city indicators can be easily achieved like: diversity, connectivity and social cohesion.

These Indicators can be applied in another place and the results can be shown in different percentage spatial strategy according to the content and efficiency of the place, and place competence concept, this led to design a spatial strategy according the place characteristics and its own components.

The city need terrorism awareness training to detect threats at the earliest stage (here the temporal dimension is very important); speed of recovery depends on strong Interrelated, relationships between institution's and population.

\section{References}

[1] world urban campaign, The City We Need 2.0, Prague-Czech,2016.

[2] Paizs:Franziska, Urban Planning after Terrorism, technical university of berlin,2012.

[3] Patel:Ronak ,Nosal:Leah,Defining the Resilient City, United Nations University ,Centre for Policy Research,USA,2016.

[4] K. Jha; Abhas \& two others, Building Urban Resilience Principles, Tools, and Practice, International Bank for Reconstruction and Development, Washington, 2013..

[5] Anand Asokan:Vivek \& two others, Introducing Flexibility to Complex, Resilient Socio-Ecological Systems: A Comparative Analysis of Economics, Flexible Manufacturing Systems, Evolutionary Biology, and Supply Chain Management, Sustainability journal, 2017.

[6] Linkov: Igor,Manuel:Jose,Resilience And Risk, University Of Lisbon,Portugal,Springer Publishing,2017,P55

[7] Patel: Ronak, Nosal, Leah,Defining the Resilient City, United Nations University Centre for Policy Research, USA ,2016.

[8] Koren :david \& two others, Proposal for Holistic Assessment of Urban System Resilience to Natural Disasters, Materials Science and Engineer, , journal citation and DOI. Published under licence by IOP Publishing Ltd, no: 245,2015.

[9] Feliciotti: Alessandra \& two others, Design for change: five proxies for resilience in the urban form, Thailand ,2010.

[10] Anand Asokan:Vivek \& two others, Introducing Flexibility to Complex, Resilient Socio-Ecological Systems: A Comparative Analysis of Economics, Flexible Manufacturing Systems, Evolutionary Biology, and Supply Chain Management, Sustainability journal, 2017.

[11] The Rockefeller Foundation, City Resilience Framework- Arup, 2015

[12] Hauge Simonsen: Sturle \& twelve others, Applying resilience thinking, Stockholm Resilience Centre,Stockholm university,2013.

[13] The Rockefeller Foundation, City Resilience Framework- Arup, 2016

[14] Esposito:frederic, secucities cities against terrorism, uropean Forum for Urban Safety,2007.

[15] United nations human settlements program, fact sheet urban safety and security, 2016.

[16] Terrorism studies free book, university of st. anderws,routledge publishing,2015,p77.

[17] Ozdamar:ozgur,theorizing terrorist behavior: major approaches and their characteristics, defence against terrorism review, vol. 1, no. 2,turkey 2008.

[18] The Program promotes the notion that better-connected, integrated and inclusive compact cities are the resilient safest cities, 2006.

[19] United nations human settlements program, fact sheet urban safety and security, 2017

[20] Buus-Hansen;Sofia \& five others ,Nordic Safe Cities Guide, The Nordic Council of Ministers, 2017. 
[21] Government of Canada report, building resilience against terrorism (Canada's counter-terrorism strategy), no.: ps4-104/2015.

[22] Government of Canada report, building resilience against terrorism (Canada's counter-terrorism strategy), no.: ps4-104/2016.

[23] Shukri, Yassin Shihab, The City of Kadhimiya in Ottoman Documents During the Sixteenth Century, Journal of the Faculty of Education for the Humanities, 7thYear, Issue 12, 2013.

[24] al- Shammari :wasan Hussein Ali, "The feeling of alienation in the traditional urban fabric of Kadhimiya city case study", Master Thesis, University of Baghdad, Center of Urban and Regional Planning, 2015,p100 